\title{
Strategi Pengendalian Pascapanen Mutu Tomat (Solanum lycopersicum) di Desa Angseri Kabupaten Tabanan Bali
}

\section{Postharvest Control Strategis of Quality Tomato (Solanum lycopersicum) in Angseri Village Tabanan Bali District}

\author{
Jun Marito Siahaan, I Gusti Ngurah Apriadi Aviantara*, I Wayan Tika \\ Program Studi Teknik Pertanian, Fakultas Teknologi Pertanian Universitas Udayana, Badung, Bali, Indonesia \\ *email: apriadiaviantara@gmail.com
}

\begin{abstract}
Tingginya kerusakan tomat selama pascapanen merupakan salah satu permasalahan yang dihadapi dalam memenuhi harapan konsumen. Pengendalian pascapanen merupakan kegiatan akhir yang harus dilakukan untuk dapat menjaga mutu tomat tetap dalam kondisi baik. Tujuan penelitian ini adalah mengindentifikasi kepentingan dan kepuasan konsumen yang menjadi atribut kunci serta menganalisis penyebab kemunduran mutu tomat dan menganalisis strategi yang tepat untuk mengendalikan mutu tomat. Kepentingan dan kepuasan konsumen akan mutu tomat dikonversikan dengan metode IPA (Importance Performance Analysis). Atribut mutu tersebut yaitu tampilan segar, kebersihan kulit buah, warna kulit buah, rasa manis dan asam, kadar air tomat, dan bebas dari rasa asing. Penurunan mutu tomat disebabkan oleh beberapa faktor berikut: (1) bahan baku yaitu: cara panen, perawatan setelah panen, teknir sortir, pengemasan, (2) manajemen yaitu: penerapan food safety management, (3) tenaga kerja yaitu: kurang skll, (4) lingkungan yaitu: bencana alam, iklim dan cuaca, (5) mesin dan metode yaitu: transportasi dan penyimpanan. Formulasi dan penentuan strategi prioritas dilakukan dengan pendekatan Strengths Weakness (SWOT) dan Opportunities Quantitative Strategies Planning Matrix (QSPM). Skor bobot matriks faktor internal yang diperoleh adalah 3,193 yang berarti berada pada posisi kuat sementara pada matriks faktor eksternal memperoleh skor adalah 3,125 yang berarti peluang belum diptimalkan dan ancaman masih belum dapat diatasi. Prioritas tertinggi yang dapat dipilih sebagai alternatif strategi adalah penambahan modal investasi juga mengendalikan penanganan budidaya dan pascapanen di optimalkan serta memproduksi tomat yang berkualitas dan juga memanfaatkan teknologi terbarukan dengan bobot sebesar 6,019.
\end{abstract}

Kata kunci: tomat, kontrol kualitas, strategi, keinginan konsumen

The high potential of damaged tomatoes during postharvest is one of the mostly faced problem in satisfying customer expectation. Postharvest handling is the final step that required to maintain good quality of tomatoes. The purpose of this study to identify customers need and satisfaction, analyze the cause of tomatoes quality deterioration and analyze the right strategies to control quality of tomatoes. The customers need and satisfaction converted using IPA (Importance Performance Analysis) method. The quality attributes as follow: fresh, clean, color, sweet and acid taste, moisture content, and no extraneous taste. The quality deterioration of tomatoes caused some of factors such as : (1) raw material: harvest method, postharvest handling, sorting method, packaging; (2) management system : food safety management application; (3) human resources : training and skills; (4) environment : natural disaster, climate and weather change; (5) equipment and method application : transportation and storage method. The formulation and strategies determination using Strengths Weakness Opportunities and Threats (SWOT) and Opportunities Quantitative Strategies Planning Matrix (QSPM) approaches. The final internal factor matrix is 3,193 which means on strong position and the final external factor matrix is 3,125 which means the opportunities are not fully optimized yet and the threats are not solved. The highest priorities that can be chosen as the alternative strategy are increasing investment assets while controlling cultivation development and optimized postharvest practices to produce the best quality of tomatoes using renewable technology up to 6,019 .

Keyword: tomato, quality control, strategi, customer desires

\section{PENDAHULUAN}

Tomat merupakan produk hortikultura yang mudah rusak (perishable). Tomat mengandung kadar air yang cukup tinggi yaitu $94 \%$ dari $100 \mathrm{~g}$ pada tomat yang sudah matang (Cahyono, 2008). Tomat yang sudah dipanen akan sangat rentan mengalami kerusakan mekanis, fisiologis dan patologis apabila tidak dilakukan penanganan dan pengendalian pascapanen yang tepat. Pengendalian mutu ditujukan 
untuk mengurangi kerusakan atau cacat pada hasil produksi berdasarkan penyebab kerusakan (Christine, 2016). Penentuan mutu buah didasarkan pada kesehatan, kebersihan, ukuran, berat, warna, bentuk, kemasakan, tidak adanya benda asing dan penyakit, tidak adanya kerusakan oleh serangga, dan luka mekanik (Yanti, 2016). Menurut Supriati dan Siregar (2015), besarnya kerusakan buah tomat setelah panen berkisar $20-50 \%$, buah tomat yang dipanen setelah timbul warna $10-20 \%$ hanya akan bertahan maksimal $7-8$ hari pada suhu kamar jika penyimpanannya bagus.

Kabupaten Tabanan, Bali merupakan salah satu daerah penyumbang produksi tomat terbanyak selama 5 tahun terakhir yaitu 52.711 ton. Desa angseri adalah salah satu desa yang membudidayakan tomat karena berada pada kondisi iklim dan cuaca yang baik untuk membudidayakan tanaman tomat. Permasalahan yang terjadi pada tomat yang diproduksi dari desa Angseri adalah pengendalian pascapanen pada setiap pelaku disepanjang rantai distribusi tomat masih belum maksimal. Hal ini menyebabkan tingginya lossess selama pascapanen tomat. Kerusakan yang terjadi pada tomat adalah kerusakan fisik, mekanis, fisiologis dan pantologis. Oleh sebab itu pengendalian pascapanen tomat sangat perlu dilakukan dalam upaya penekanan lossess baik kuantitas maupun kualitas dengan perbaikan dan penerapan teknologi penanganan pascapanen (Musaddad, 2003).

Tujuan penelitian ini adalah mengetahui kepentingan mutu dan kepuasan konsumen serta mengindentifikasi faktor penyebab penurunan mutu tomat dan menyusun faktor strategi alternatif dalam pengendalian paspapanen tomat. Manfaat penelitian ini adalah diharapkan mampu menjadi masukan dan sumber informasi dalam pengendalian paspapanen tomat dalam memenuhi keinginan dan harapan konsumen terhadap mutu tomat.

\section{METODE}

\section{Lokasi dan Waktu Kegiatan}

Penelitian ini dilakukan di Desa Angseri Kabupaten Tabanan, Kecamatan Baturiti, Bali mencakup pendistribusian tomat. Desa Angseri merupakan salah satu daerah yang banyak terdapat petani tomat. Penelitian ini dilaksanakan pada bulan Juni sampai Agustus 2019.

\section{Populasi dan Sampel Penelitian}

Populasi yang digunakan dalam penelitian ini ditentukan dengan metode Purposive sampling dimana teknik pengambilan sampel dilakukan dengan menentukan responden yang memenuhi kriteria terhadap sampel yang diperlukan terutama orangorang ahli (Silalahi, 1999). Responden penelitian ini merupakan petani tomat, pengepul, pemasok, dan konsumen supermarket serta pakar ahli. Responden konsumen diambil dari konsumen supermarket Tiara Dewata. Responden merupakan konsumen yang membeli tomat di Tiara Dewata diasumsikan mencapai kurang dari 50 orang setiap harinya. Menurut Roscoe (1975) dalam Umar Sekaran (2006) mengatakan bahwa jumlah sampel diatas 30 dan kurang dari 500 adalah tepat untuk kebanyakan penelitian.

Menurut Umar (2010) cara pengambilan jumlah sampel dari suatu popilasi dilakukan dengan beberapa cara yaitu salah satunya adalah dengan menggunakan metode solvin. Berdasarkan rumus solvin tersebut dengan tingkat kesalahan yaitu $5 \%$ maka jumlah sampel responden adalah 45 orang.

$$
\begin{aligned}
& n=\frac{N}{1+N(e)^{2}} \\
& \text { Keterangan : } \\
& \mathrm{n}=\text { Ukuran sampel; } \\
& \mathrm{N}=\text { Ukuran populasi } \\
& \mathrm{E}=\text { Margin of error } 5 \% \\
& n=\frac{50}{1+50(5 \%)^{2}}=44,44 \approx 45
\end{aligned}
$$

\section{Pelaksanaan Penelitian}

Pengumpulan data dalam penelitian ini menggunakan kuesioner survey pengamatan langsung dan wawancara langsung yaitu kepada petani, pengepul, pemasok dan retailer. Selain itu juga dilakukan penyebaran kuesioner kepada konsumen supermarket dan kepada pakar. Kuesioner disusun berdasarkan komponen-komponen yang diperlukan untuk analisis data. Kuesioner merupakan pengumpulan data yang dilakukan dengan mengajukan pertanyaan atau pernyataan kepada responden secara tertulis untuk dapat dijawab langsung oleh responden (Sugiyono, 2005).

\section{Analisis Data}

Data yang digunakan dalam penelitian ini berupa data primer dan sekunder. Data primer diperoleh dengan melakukan wawancara langsung dengan melakukan penelusuran pada alur distribusi tomat dimulai dari petani tomat di Desa Angseri, pengepul, pemasok dan retailer. Analisis data penentuan tingkat kepentingan atribut mutu tomat diolah dengan menggunakan metode Importance Performance Analysis (IPA). Metode Importance Performance Analysis adalah metode analisis untuk membandingkan tingkat kinerja/pelayanan yang dirasakan oleh konsumen pengguna jasa/barang terhadap tingkat kepuasan yang diinginkan (Yola, 2013). Penyebab-penyebab 
penurunan mutu tomat dianalisis dengan menggunakan diagram ishikawa. Penyusunan strategi alternatif dianalisis dengan menggunakan metode Strengths Weakness Opportunity Threats (SWOT) yang diterjemahkan kedalam matriks IFE dan EFE. Evaluasi pengembilan strategi alternatif dianalisis dengan menggunakan dan metode Quantitave Strategies Planning Matrix (QSPM), berdasarkan key success factors internal dan eksternal yang telah diindentifikasi sebelumnya.

\section{HASIL DAN PEMBAHASAN}

\section{Gambaran Umum Lokasi Penelitian}

Desa Angseri terletak di Kecamatan Baturiti Kabupaten Tabanan Bali yang merupakan daerah yang memproduksi hasil panen tomat terbanyak yaitu 53.711 ton tomat dalam 5 tahun terakhir. Desa Angseri merupakan salah satu daerah pertanian yang terletak pada ketinggian $1240 \mathrm{~m}$ dari permukaan laut dengan temperatur suhu rata-rata 18 derajat celsius dan 24 derajat celsius pada siang hari. Sehingga menjadikan kondisi lingkungan daerah Desa Angseri berpotensi untuk membudidayakan tomat. Tomat dapat tumbuh baik pada kondisi temperatur lingkungan $23^{\circ} \mathrm{C}-29^{\circ} \mathrm{C}$. Petani di desa Angseri membudidayakan tomat dengan sistem tumpang sari. Biasanya tanaman tumpang sari yang diterapkan petani adalah cabe, sayur sawi, dan bunga.

\section{Karakteristik Responden}

Dalam penelitian ini, responden dengan jumlah sampel sebesar 45 orang yang merupakan konsumen di Tiara Dewata dengan syarat membeli atau mengkonsumsi tomat lebih dari satu kali pembelian.

Tabel 1. Uraian jumlah responden

\begin{tabular}{l|lc} 
No. & \multicolumn{1}{c|}{ Uraian } & (\%) \\
1.Jenis & Laki-laki & 2 \\
kelamin & Permempuan & 43 \\
\hline \multirow{4}{*}{ 2.Usia } & $21-25$ & 9 \\
& $26-30$ & 14 \\
& $31-35$ & 15 \\
& $36-40$ & 7 \\
\hline 3. Status & Menikah & 32 \\
pernikahan & Belum menikah & 13 \\
\hline \multirow{2}{*}{ 4. Tingkat } & SMA/SMK/MA & 5 \\
pendidikan & Diploma & 10 \\
& Sarjana (S1, S2) & 30 \\
\hline \multirow{5}{*}{ 5.Pekerjaan } & Tidak atau Belum & 2 \\
& Bekerja & 7 \\
& PNS & 18 \\
& Mahasiswa & 4 \\
& Pegawai Swasta & 14 \\
& Wiraswasta atau & 5 \\
\hline & Pengusaha & \\
& Lainnya &
\end{tabular}

\section{Kepuasan Konsumen}

Kepuasan konsumen diukur dengan menggunakan metode Customer Satisfaction Indeks (CSI). CSI dihitung dengan menentukan Mean Importance Score (MIS), Mean Satisfacti on Score (MSS) Weight Factors (WF) Weight Score (WS) Weight Total (WT) (Siagian dalam Anggraeni, 2015).

Tabel 2. Kriteria nilai Customer Satisfaction Indeks (CSI)

\begin{tabular}{|c|c|}
\hline Nilai indeks (100\%) & Kriteria \\
\hline $\begin{array}{c}80 \%<\text { satisfaction indeks } \\
\leq 100 \%\end{array}$ & Sangat puas \\
\hline $\begin{array}{c}60 \%<\text { satisfaction indeks } \\
\leq 80 \%\end{array}$ & Puas \\
\hline $\begin{array}{c}40 \%<\text { satisfaction indeks } \\
\leq 60 \%\end{array}$ & Cukup puas \\
\hline $\begin{array}{c}20 \%<\text { satisfaction indeks } \\
\leq 40 \%\end{array}$ & Kurang puas \\
\hline $\begin{array}{c}0 \%<\text { satisfaction indeks } \leq \\
20 \%\end{array}$ & Adil puas \\
\hline
\end{tabular}

Tingkat kepuasan konsumen terhadap atribut mutu tomat yang disebar dapat dilihat pada Tabel 1 . Perhitungan nilai CSI dianalisis dengan menggunakan skor rata-rata tingkat kepentigan dan kepuasan konsumen dari masing-masing atribut mutu.

Tabel 3. Kepuasan konsumen terhadap mutu tomat yang beredar dipasar secara keseluruhan

\begin{tabular}{|c|c|c|c|c|}
\hline Atribut Kualitas & MIS & WF & WS & MSS \\
\hline Permukaan mulus & 4,27 & 7,57 & 33,33 & 4,40 \\
\hline Tampilan segar & 4,73 & 8,40 & 34,92 & 4,16 \\
\hline $\begin{array}{l}\text { Kebersihan kulit } \\
\text { buah }\end{array}$ & 4,47 & 7,93 & 31,89 & 4,02 \\
\hline Bentuk buah & 3,60 & 6,39 & 26,41 & 4,13 \\
\hline Ukuran buah & 3,69 & 6,55 & 26,63 & 4,07 \\
\hline Warna kulit buah & 4,42 & 7,85 & 32,80 & 4,18 \\
\hline $\begin{array}{l}\text { Warna daging } \\
\text { buah }\end{array}$ & 4,42 & 7,85 & 33,67 & 4,29 \\
\hline Tekstur kulit buah & 4,44 & 7,89 & 33,31 & 4,22 \\
\hline $\begin{array}{l}\text { Tekstur daging } \\
\text { buah }\end{array}$ & 4,44 & 7,89 & 34,01 & 4,31 \\
\hline $\begin{array}{l}\text { Rasa manis dan } \\
\text { asam }\end{array}$ & 4,38 & 7,77 & 31,60 & 4,07 \\
\hline Kadar air tomat & 4,18 & 7,42 & 30,65 & 4,13 \\
\hline $\begin{array}{l}\text { Bebas dari hama } \\
\text { dan penyakit }\end{array}$ & 4,73 & 8,40 & 35,85 & 4,27 \\
\hline $\begin{array}{l}\text { Bebas dari rasa } \\
\text { asing }\end{array}$ & 4,56 & 8,09 & 33,25 & 4,11 \\
\hline WT & \multicolumn{4}{|c|}{418,32} \\
\hline CSI & \multicolumn{4}{|c|}{83,66} \\
\hline
\end{tabular}

Berdasarkan perhitungan, diperoleh nilai CSI sebesar $83.66 \%$ yang berarti secara keseluruhan konsumen sudah merasa puas terhadap kualitas tomat yang beredar dipasaran. Hal ini disebabkan karena kualitas tomat yang tersedia di pasar sudah memiliki mutu yang cukup baik dan memenuhi harapan konsumen. Namun peningkatan mutu harus tetap dikendalikan 
dengan baik oleh petani, pegepul, dan retailer untuk menjaga kepercayaan dan loyalitas konsumen terhadap mutu tomat yang diproduksi.

Analisis Kepentingan Kinerja (IPA)
Metode IPA ini dapat mengkelaskan atribut mutu pada 4 kuadran sesuai dengan mengkonversikan tingkat kepentingan dengan tingkat kepuasan konsumen terhadap masing-masing atribut mutu.

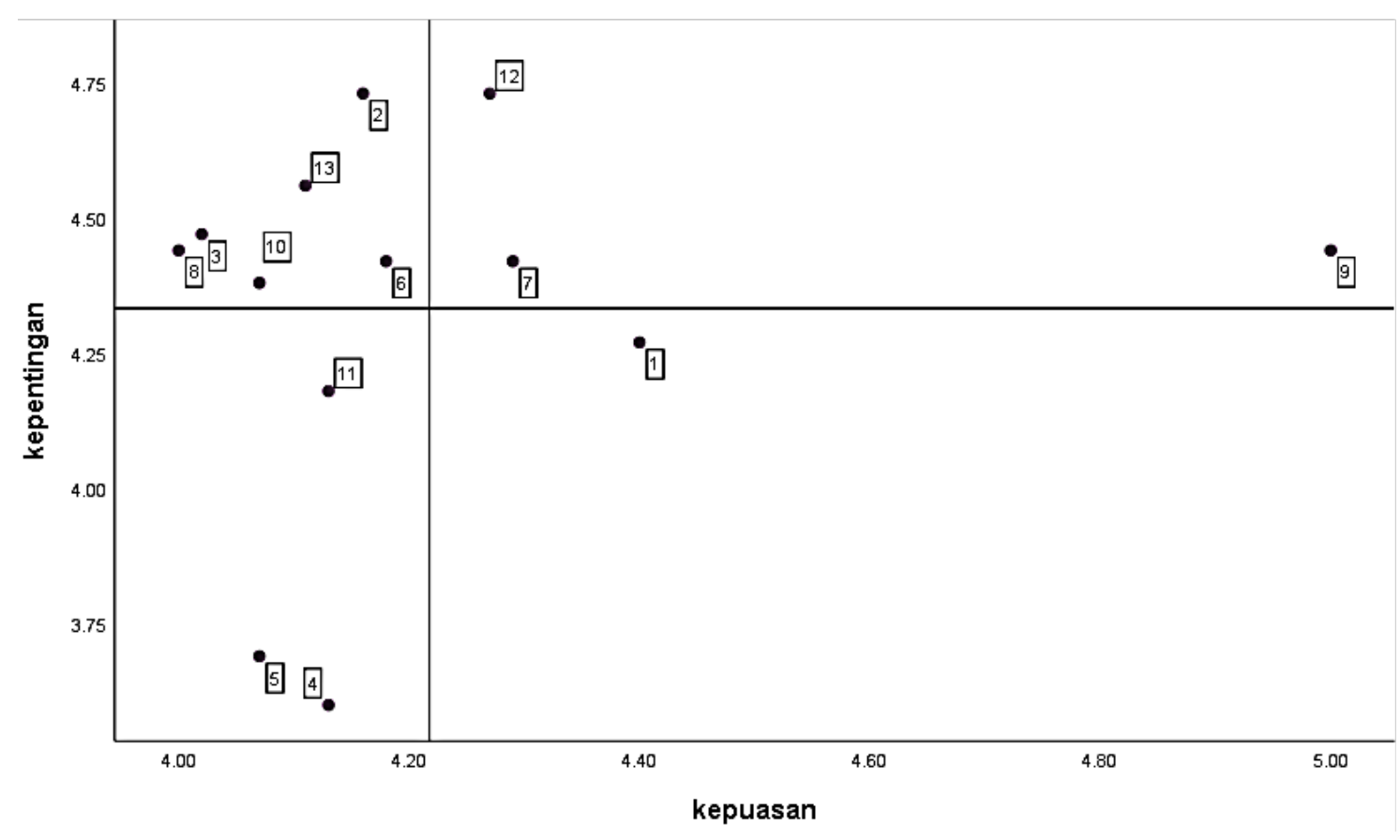

Gambar 1. Diagram Kartesian

Dari hasil matrik metode Importance Performance Analysis (IPA) tingkat kepentingan atribut mutu pada kuadran 1 terdapat 6 atribut mutu yang perlu diperbaiki yaitu (2) tampilan segar, (3) kebersihan kulit buah, (6) warna kulit buah, (8) tekstur kulit buah, (10) rasa manis dan asam, (13) bebas dari rasa asing. Pada kuadran 2 terdapat 3 atribut mutu yang kinerjanya sudah bagus dan perlu dipertahankan yaitu (7) warna daging buah, (9) tekstur daging buah, (12) bebas dari hama dan penyakit. Pada kuadran 3 terdapat 2 atribut mutu yang kinerjanya masih kurang tetapi belum terlalu penting untuk konsumen yaitu (4) bentuk buah, (5) ukuran buah, (11) kadar air tomat, sedangkan pada kuadran 4 atribut mutu yang kinerjanya terlalu bagus dan tidak terlalu penting menurut responden adalah (1) permukaan mulus.

\section{Indentifikasi faktor-faktor yang mempengaruhi kemunduran mutu tomat}

Berdasarkan hasil penelitian (Gambar 1) pada kuadran 1 masih terdapat 6 atribut mutu yang perlu diperbaiki dan dikendalikan penanganan pascapanennya agar dapat menjaga mutu tetap optimal. Kehilangan hasil panen dipengaruhi oleh banyak faktor. Kehilangan (losses) hasil terjadi pada sepanjang proses produksi dimulai dari prapanen sampai pascapanen hingga tomat sampai ke tangan konsumen. Losses dapat dikendalikan dengan perlakuan pengendalian yang tepat dan benar sehingga kerugian hasil panen dapat di minimalisir. Terdapat enam kendala utama faktor-faktor yang mempengaruhi penurunan mutu buah tomat yang diidentifikasi dengan menggunakan diagram ishikawa yaitu bahan baku, manajemen, tenaga kerja, lingkungan, metode dan mesin. Indentifikasi faktor penyebab penurunan mutu menggunakan diagram ishikawa, diperoleh 11 faktor penyebab yang mengakibatkan terjadinya kemunduran mutu pada buah tomat dalam Gambar 2. Berdasarkan identifikasi faktor-faktor yang mempengaruhi penurunan mutu tomat dengan menggunakan diagram ishikawa terdapat hal-hal yang perlu diperhatikan kinerjanya yaitu; 


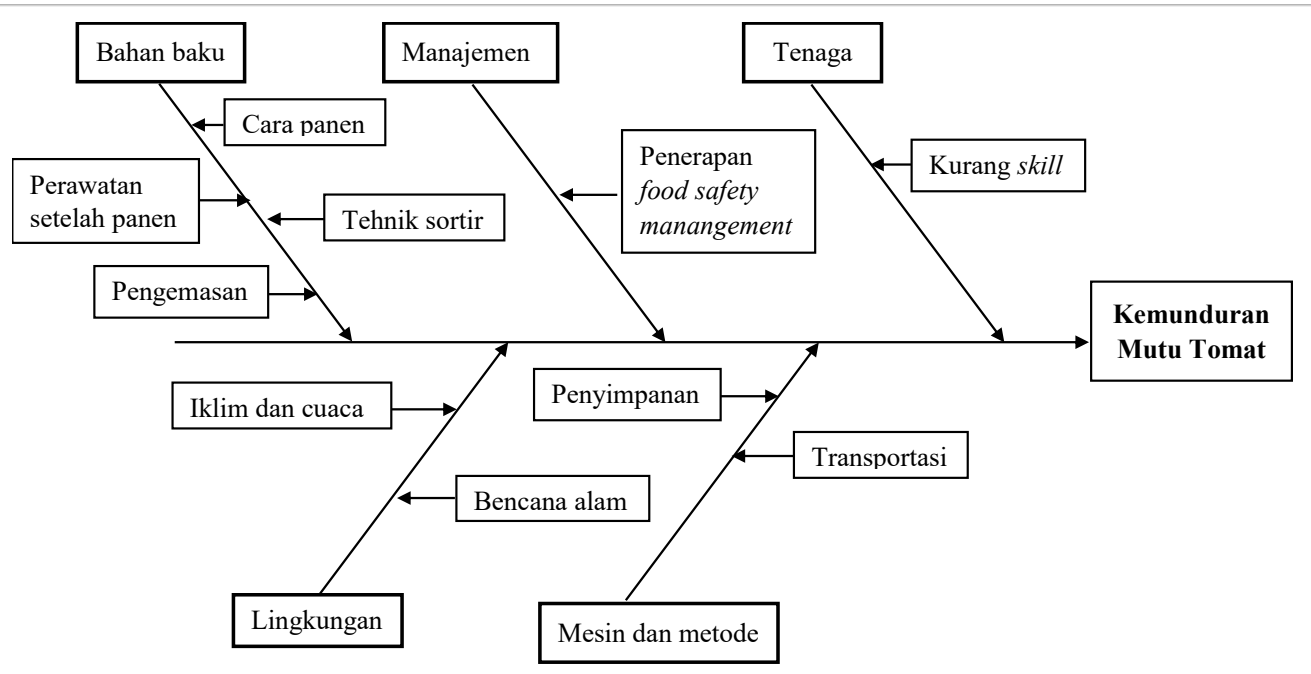

Gambar 2. Diagram Ishikawa

\section{Bahan Baku (Material)}

Petani memanen tomat dengan cara memetik dan memelintir batang buah tomat. Hal ini dapat meningkatkan resiko kerusakan fisik pada tomat dan tanaman tomat. Selain cara pemanenan tomat yang kurang tepat, masih terdapat pengepul dan pemasok yang menyimpan tomat diluar ruangan yang terkena sinar matahari langsung. Wadah yang digunakan dalam pengangkutan pendistribusian tomat adalah keranjang yang dilapisi dengan koran. Hal ini dapat merusak mutu tomat dikarenakan adanya tekanan, getaran dan guncangan selama transportasi. Menurut Widhiantari (2013) tomat akan mengalami kerusakan sebesar 21,8\% menggunakan metode pengemasan dengan keranjang. Kerusakan yang diharapkan adalah sekecil mungkin. Widhiantari (2016) mengatakan penggunaan bahan pengisi kombinasi serat eceng gondok dan pelepah pisang dapat meredam getaran wadah yang digunakan selama transportasi pengangkutan dengan nilai persentase kerusakan sebesar $16 \%$ pada buah tomat.

\section{Manajemen}

Penerapan sistem manajemen antara petani, pengepul, pemasok, dan retailer masih kurang. Seperti kurangnya penerapan Just In Time (JIT). Ketepatan waktu pengiriman dalam mendistribusikan tomat dari petani ke konsumen akhir yang terlalu lama. Hal ini disebabkan karena penyimpanan tomat cukup lama pada pengepul dan retailer. Sehingga selama penyimpanan tomat mengalami kematangan dan kemunduran mutu sebelum tomat sampai kepada konsumen. Selain itu kurangnya penerapan Good Handling Practice (GHP) seperti pengemasan tomat oleh pengepul dan pemasok juga masih kurang efektif. Pengepul meletakkan tomat dibawah sinar matahari langsung, dan transportasi masih ada yang tidak menggunakan alat pendingin.

\section{Tenaga Kerja}

Kurangnya skill dan pengetahuan petani dalam budidaya tomat merupakan faktor paling mempengaruhi mutu tomat. Kendala yang dihadapi petani selama budidaya tomat adalah serangan OPT. Penggunaan greenhouse sangat disarankan dalam budidaya tomat. Menurut Kusumayati (2015), dengan menggunakan greenhouse dapat meningkatkan jumlah panen lebih tinggi dibandingkan hasil panen yang tidak menggunakan greenhouse. Penurunan mutu tomat juga disebabkan karena kurangnya skill tenaga kerja pada pengepul, pemasok dan retailer. Kedisiplinan, ketelitian dan kehati-hatian tenaga kerja pada proses sortasi dilakukan dengan melemparkan tomat kedalam keranjang yang letaknya jauh dari pekerja.

\section{Lingkungan}

Perubahahan iklim dan cuaca sangat sulit diprediksi oleh petani sehingga mempengaruhi kegiatan budidaya oleh petani yang dapat menyebabkan tidak terkendalinya penyebaran dan serangan hamapenyakit yang semakin tinggi. Selain iklim dan cuaca, kendala yang menjadi tantangan petani adalah bencana alam yaitu Gunung Agung yang terletak cukup dekat dengan lahan tanam tomat, dimana saat gunung mengalami erupsi, abu vulkanik masih sampai dan mencapai lahan tanam tomat yang menyebabkan kelayuan bahkan kematian pada tanaman tomat.

\section{Mesin dan Metode}

Alat penyimpanan dan transportasi yang digunakan oleh pengepul adalah pick up yang tidak berpendingin. Sementara tomat harus disimpan pada suhu $5^{\circ} \mathrm{C}$ baik selama pengangkutan maupun penyimpanan harus dilengkapi dengan alat pendingin untuk menjaga kesegaran dan mengendalikan respirasi tomat. 


\section{Strategi Peningkatan Kualitas}

Strategi peningkatan kualitas dilakukan dengan menggunakan metode SWOT (Strengths Weakness Opportunity Threats) dan QSPM (Quantitative Strategy Planning Matrix). Alternatif-alternatif penanganan pascapanen dianalisis dengan matriks SWOT. Penentuan keputusan alternatif strategi paling efektif menggunakan QSPM.

\section{Matriks IFE (Internal Factor Evaluation)}

Analisis matriks IFE bertujuan untuk menganalisis faktor-faktor internal yang disusun dari identifikasi faktor-faktor kekuatan dan kelemahan dalam budidaya dan penanganan pascapanen tomat di desa Angseri.

Tabel 4. Faktor-faktor matriks IFE

\section{Faktor-faktor Internal}

\section{Kekuatan}

Konsumsi tomat tinggi

0.112

3.20

0.358

Waktu tempuh dan jarak pengiriman pendek

0.112

3.20

0.358

Dapat diolah menjadi banyak jenis produk baru

seperti jus, saus, dan produk kecantikan

$\begin{array}{lll}0.126 & 3.60 & \mathbf{0 . 4 5 3}\end{array}$

Kandungan gizi tinggi

0.105

3.00

0.315

\section{Kelemahan}

Kurangnya skill petani

0.112

3.20

0.358

Tomat mudah busuk

0.119

3.40

0.404

Keterbatasan modal usaha

0.098

2.80

0.274

Transportasi tidak efisien

0.105

3.00

0.315

Penanganan pascapanen masih kurang

0.112

0.358

\section{Total}

1.00

3.193

Berdasarkan matrik IFE diatas didapatkan total skor terbobot sebesar 3,193. Menurut Umar (2008), jika skor terbobot diatas 2,50 menandakan bahwa secara internal jaringan distribusi tomat berada pada posisi kuat. Hasil penilaian matirks faktor-faktor internal adalah 3,193 yang berarti berada pada posisi kuat. Kekuatan utama adalah buah tomat dapat diolah menjadi banyak jenis produk baru seperti jus, saus, dan produk kecantikan dengan skor sebesar 0,453. Kekuatan pada faktor internal yang terpilih disebabkan karena potensi buah tomat sangat besar untuk dapat diolah lebih lanjut lagi. Menurut Agung dalam situs Kementrian Pertanian Republik Indonesia (https://pertanian.go.id) menyatakan bahwa produk olahan dari tomat memiliki banyak peminat, selain cita rasa tomat yang khas, olahan tomat seperti dodol tomat, manisan tomat, dan tomat kurma dapat dijadikan buah tangan dengan nilai jual yang baik.

Kelemahan utama yang dihadapi adalah tomat mudah busuk dengan skor terbesar 0,404. Kelemahan yang terpilih pada faktor internal ini disebabkan karena tomat mengandung kadar air yang sangat tinggi yaitu $94 \%$ sehingga sangat rentan mengalami kebusukan. Selain itu kerusakan mekanis, penanganan pascapanen tomat yang tidak tepat sangat mudah menyebabkan penurunan mutu pada tomat.

\section{Matriks EFE (External Factor Evaluation)}

Analisis matriks EFE bertujuan untuk menganalisis faktor-faktor eksternal yang disusun dari identifikasi faktor-faktor peluang dan ancaman dalam budidaya dan penanganan pascapanen tomat di desa Angseri.

Tabel 5. Matriks Faktor-Fakor Eksternal

\begin{tabular}{|c|c|c|c|}
\hline Faktor-faktor Eksternal & Bobot & Rating & Skor Terbobot \\
\hline \multicolumn{4}{|l|}{ Peluang } \\
\hline Angka kebutuhan ekspor buah tomat tinggi & 0.161 & 3.00 & 0.484 \\
\hline Perkembangan teknologi & 0.183 & 3.40 & 0.622 \\
\hline Dapat dikonsumsi semua kalangan & 0.161 & 3.00 & 0.484 \\
\hline \multicolumn{4}{|l|}{ Ancaman } \\
\hline Serangan OPT dan penyakit tanaman tomat & 0.183 & 3.40 & 0.622 \\
\hline Perubahan iklim dan cuaca & 0.172 & 3.20 & 0.551 \\
\hline Bencana alam & 0.140 & 2.60 & 0.363 \\
\hline Total & 1.00 & & 3.125 \\
\hline
\end{tabular}


Berdasarkan matrik IFE diatas didapatkan total skor terbobot sebesar 3,125. Menurut Umar (2008), apabila skor total 4,00 maka pelaku kegiatan distribusi tomat merespon sangat baik peluangpeluang yang ada dan menghindari ancamanancaman yang ada. Peluang utama yang harus dimanfaatkan dengan baik adalah perkembangan teknologi yaitu sebesar 0,622. Perkembangan teknologi yang sudah maju dan mampu memfasilitasi dalam penanganan mutu buah tomat baik dari prapanen hingga pascapanen sudah ada, namun masih kurang dimanfaatkan. Oleh sebab itu pemanfaatan perkembangan teknologi merupakan potensi dan peluang yang sangat baik dalam menghasilakan tomat yang berkualitas. Contoh teknologi yang belum dimanfaatkan adalah greenhouse. Hal ini dibuktikan dengan penelitian Kusumayati (2015) Teknik greenhouse mampu meningkatkan hasil total jumlah panen lebih tinggi dibandingkan tidak menggunakan greenhouse.

Ancaman utama yang harus dihadapi adalah serangan OPT dan penyakit tanaman tomat dengan skor sebesar 0,622. Penelitian yang dilakukan oleh Santi (2015) menyatakan dampak serangan OPT dan hama penyakit mengakibatkan penurunan hasil panen yang tinggi. Serangan hama ringan dapat mengakibatkan penurunan panen $10-29 \%$, sedang $30-54 \%$ dan tingkat serangan berat $55-100 \%$.

Setelah dilakukan indentifikasi terhadap faktorfaktor internal dan eksternal maka disusun matriks SWOT dalam pengendalian pascapanen buah tomat. Matriks SWOT dalam pengendalian pascapanen tomat terdapat empat strategi, antara lain:

a. Strategi SO (Strengths - Opportunities) : meningkatkann kualitas tomat dan memperluas jaringan distribusi dan memanfaatkan teknologi dalam meningkatan jumlah produksi tomat yang berkualitas.

b. Strategi WO (Weaknesses - Opportunities) : penambahan modal investasi, mengendalikan penanganan budidaya dan pascapanen di optimalkan, memproduksi tomat yang berkualitas dan memanfaatkan teknologi terbarukan.

c. Strategi ST (Strengths - Threats) : menjalin hubungan yang baik dengan antara petani, pengepul, pemasok, dan retailer. Pengendalian opt sesuai dengan aturan serta meningkatkan wawasan petani dalam menambah jumlah produksi tomat.

d. Strategi WT (Weaknesses - Threats) : memelihara dan mengendalikan prapanen dan pascapanen tomat untuk menjaga mutu tomat sebelum dan sesudah panen.

\section{Strategi Pengambilan Keputusan}

Strategi untuk pengambilan keputusan dalam pengendalian pascapanen mutu tomat dalam analisis QSPM diperoleh dari matriks SWOT, antara lain:

1. Strategi 1 (S1) adalah meningkatkan kualitas tomat dan memperluas jaringan distribusi dan memanfaatkan teknologi dalam meningkatkan jumlah produksi tomat yang berkualitas.

2. Strategi 2 (S2) adalah penambahan modal investasi juga mengendalikan penanganan budidaya dan pascapanen di optimalkan serta memproduksi tomat yang berkualitas dan juga memanfaatkan teknologi terbarukan.

3. Strategi 3 (S3) adalah menjalankan organisasi petani (Gapoktan) dengan maksimal, meningkatkan melakukan penyuluhan.

4. Strategi 4 (S4) adalah menjalin hubungan dengan baik antara petani, pengepul, pemasok, dan retailer. Pengendalian OPT sesuai dengan aturan.

5. Strategi 5 (S5) adalah meningkatkan wawasan petani dalam menambah jumlah produksi tomat.

6. Strategi 6 (S6) adalah memelihara dan mengendalikan prapanen dan pascapanen tomat untuk menjaga mutu tomat sebelum dan sesudah panen.

Setelah dilakukan indentifikasi terhadap faktorfaktor internal dan eksternal maka disusun matriks SWOT dalam pengendalian pascapanen buah tomat pada Tabel 5. Analisis SWOT bersandar pada informasi yang diturunkan dari tahap input untuk mencocokkan peluang dan ancaman eksternal dengan kekuatan dan kelemahan internal. Formulasi strategi dilakukan dengan mengkombinasi bebagai faktor yang telah diindentifikasi. Hasil formulasi strategi dikelompokan menjadi empat kelompok yang terdiri atas : strategi kekuatan- peluang (S-O), strategi kekuatan-kekuatan (S-T), strategi kelemahan-peluang (W-O), strategi kelemahanancaman (W-T). Pengelompokan strategi dapat dilihat pada Tabel 6 .

Nilai Total Attractiveness Score (TAS) dari hasil perhitungan alternatif strategi yang tertinggi menunjukkan alternatif tersebut merupakan strategi yang menjadi pilihan utama dan nilai TAS yang terendah merupakan alternatif strategi pilihan terakhir untuk dipilih. Hasil pembobotan alternatif strategi dengan metode QSPM dari gabungan 5 pakar dapat dilihat pada Tabel 7 
Tabel 6. Matriks SWOT pengendalian pascapanen tomat

\begin{tabular}{ll} 
INTERNAL & \multicolumn{1}{c}{ KEKUATAN / STRENGTHS } \\
& 1. Konsumsi tomat tinggi \\
2. Produksi tomat di Tabanan tinggi \\
3. Dapat diolah menjadi banyak jenis produk \\
baru seperti jus, saus dan produk kecantikan
\end{tabular}

\section{PELUANG /}

\section{OPPORTUNITIES}

1. Angka kebutuhan ekspor buah tomat tinggi

2. Perkembangan teknologi

3. Dapat dikonsumsi semua kalangan

\section{STRATEGI SO}

1. Meningkatkan kualitas tomat dan memperluas jaringan distribusi dan memanfaatkan teknologi dalam meningkatkan jumlah produksi tomat yang berkualitas (S1, S3, S4) $(\mathrm{O} 1, \mathrm{O} 2)$

\section{ANCAMAN / THREATS \\ 1. Serangan OPT dan penyakit tanaman tomat \\ 2. Perubahan iklim dan cuaca \\ 3. Bencana alam}

\section{STRATEGI ST}

1. Menjalin hubungan dengan baik antara petani, pengepul, pemasok, dan retailer. Pengendalian OPT sesuai dengan aturan (S2, $\mathrm{S} 3)(\mathrm{T} 1, \mathrm{~T} 2)$

2. Meningkatkan wawasan petani dalam menamsupermbah jumlah produksi tomat $(\mathrm{S} 1, \mathrm{~S} 4)(\mathrm{T} 1, \mathrm{~T} 2)$
KELEMAHAN / WEAKNESSESS

1. Kurangnya skill petani

2. Tomat mudah busuk

3. Transportasi tidak efisien

4. Kekurangan modal usaha

5. Penanganan pascapanen tidak efisien

\section{STRATEGI WO}

1. penambahan modal investasi, mengendalikan penanganan budidaya dan pascapanen di optimalkan, memproduksi tomat yang berkualitas dan memanfaatkan teknologi terbarukan (W2, W3, W4) (O1)

2. Menjalankan organisasi petani (Gapoktan) dengan maksimal, meningkatkan melakukan penyuluhan (W1, W5) (O1, O2, O3)

\section{STRATEGI WT}

1. Memelihara dan mengendalikan prapanen dan pascapanen tomat untuk menjaga mutu tomat sebelum dan sesudah panen (W2, W3, W5) (T1, $\mathrm{T} 2)$
Tabel 7. Bobot Strategi QSPM

\begin{tabular}{c|c|c} 
Strategi & Skor Bobot atau TAS & Prioritas \\
S1 (Strategi 1) & 5.586 & 2 \\
S2 (Strategi 2) & $\mathbf{6 . 0 1 9}$ & 1 \\
S3 (Strategi 3) & 4.942 & 4 \\
S4 (Strategi 4) & 4.745 & 6 \\
S5 (Strategi 5) & 5.117 & 3 \\
S6 (Strategi 6) & 4.872 & 5 \\
\hline
\end{tabular}

Berdasarkan hasil analisis perhitungan nilai TAS pada Tabel diatas strategi yang memperoleh nilai tertinggi merupakan strategi pilihan utama adalah strategi 2 (S2) yaitu adalah penambahan modal investasi, mengendalikan penanganan budidaya dan pascapanen di optimalkan, memproduksi tomat yang berkualitas dan memanfaatkan teknologi terbarukan (nilai TAS sebesar 6,019). Strategi tersebut diharapkan mampu menghasilkan tomat yang berkualitas dengan lebih memperhatikan penanganan budidaya dan pengendalian pascapanen tomat serta memanfaatkan perkembangan teknologi.

\section{Implikasi Manajerial}

Berdasarkan hasil penelitian ini, terdapat enam atribut mutu yang diperoleh dari konsumen dan perlu segera diperbaiki secepat mungkin yaitu tampilan segar, kebersihan kulit buah, warna kulit buah, rasa manis dan asam, kadar air tomat, dan bebas dari rasa asing. Keenam mutu ini terdapat pada kuadran 1 dimana kepentingan konsumen tinggi namun tingkat kepuasan konsumen rendah. Untuk memperbaiki mutu keenam atribut pada kuadran 1 dapat dilakukan dengan berbagai cara memilih varietas tomat unggulan, membersihkan tomat dari kotoran dan benda asing, mengendalikan kematangan buah tomat pada saat pemanenan dan menyimpan tomat pada suhu yang tepat. Dengan perlakuan tersebut, mutu buah tomat akan terkendali sehingga kepuasan konsumen akan meningkat.

Hasil indentifikasi penyebab kemunduran mutu tomat dengan menggunakan diagram ishikawa dipengaruhi oleh enam faktor yaitu tenaga kerja, bahan baku, manajemen, lingkungan, mesin dan metode penanganan mutu buah tomat. Faktor-faktor tersebut harus lebih difokuskan pengendaliannya dengan memanfaatkan bantuan teknologi yang terbarukan.

Faktor internal terbesar adalah tomat dapat diolah menjadi banyak jenis produk baru seperti jus, saus, dan produk kecantikan. Kekuatan ini harus dimanfaatkan seoptimal mungkin dengan mengolah tomat dan menjadikan produk-produk yang berbahan dasar tomat menjadi produk unggulan. Pada faktor eksternal terdapat dua faktor yang memiliki peringkat yang sama yaitu perkembangan teknologi dan serangan OPT dan penyakit tanaman tomat. Memanfaatkan peluang perkembangan teknologi sangat berpotensi besar dalam menghasilkan tomat yang berkualitas. Contoh pemanfaatan perkembangan teknologi adalah greenhouse. Penggunaan greenhouse pada budidaya tomat dapat membantu petani untuk meningkatkan jumlah produksi tomat yang berkualias. 


\section{KESIMPULAN}

\section{Kesimpulan}

Berdasarkan hasil analisis yang telah dilakukan selama penelitian maka dapat diperoleh kesimpulan sebagai berikut.

Metode Importance Performance Analysis (IPA) pada kudran 1 menunjukkan bahwa masih terdapat atribut mutu yang mutunya perlu dikendalikan dan perlu ditingkatkan yaitu; tampilan segar, kebersihan kulit buah, warna kulit buah, rasa manis dan asam, kadar air tomat, dan bebas dari rasa asing.

Indentifikasi faktor penyebab penurunan mutu menggunakan diagram ishikawa memperoleh 11 faktor penyebab yang mengakibatkan terjadinya kemunduran mutu pada buah tomat. Faktor penyebab tersebut adalah cara panen, perawatan tomat setelah panen, teknik sortasir yang dilakukan oleh tenaga kerja, kemasan yang digunakan dalam penyimpanan tomat, kurangnya penerapan food safety managemet, kurangnya skill petani, iklim dan cuaca, bencana alam, penyimpanan, kurangnya pengendalian mutu, dan transportasi yang digunakan.

Hasil perhitungan skor pada matriks IFE menunjukkan kekuatan yang paling tinggi adalah tomat dapat diolah menjadi banyak jenis produk baru seperti jus, saus, dan produk kecantikan (skor 0,453), sementara kelemahan dengan nilai tertinggi adalah tomat mudah busuk (skor 0,404). Hasil perhitungan skor pada matriks EFE menunjukkan perkembangan teknologi merupakan peluang yang paling tinggi skornya (skor 0,622). Sementara pada faktor ancaman, serangan OPT dan penyakit tanaman tomat memiliki skor tertinggi (skor 0,622).

Terdapat 6 strategi alternatif yang diperoleh dari analisis matriks SWOT. Hasil analisis QSPM merumuskan strategi yang terpilih adalah strategi 2 (W-O) yaitu penambahan modal investasi, mengendalikan penanganan budidaya dan pascapanen di optimalkan, memproduksi tomat yang berkualitas dan memanfaatkan teknologi terbarukan karena mempunyai nilai Total Attractiveness Score tertinggi yaitu sebesar 6,019 yang menjadikan strategi 2 menjadi prioritas utama.

\section{Saran}

Berdasarkan hasil penelitian yang telah dilakukan, maka saran yang dapat diberikan adalah perlu adanya penambahan modal oleh petani dalam membudidayakan tomat. Petani diharapkan aktif mengikuti kegiatan penyuluhan tentang pembudidayaan agar para petani mampu meingkatkan produksinya baik dari segi kualitas maupun kuantitas. Harus adanya pengendalian pascapanen yang optimal oleh pengepul, pemasok, dan retailer dengan memanfaatkan teknologi terbarukan untuk mendapatkan hasil panen tomat yang berkualitas, sehingga mampu memenihi harapan dan kepuasan konsumen terhadap mutu tomat.

Cahyono, I. B. (2008). Tomat, Usaha Tani dan Penanganan Pasca Panen. Kanisius.

Kusumayati, N., Nurlaelih, E. E., \& Setyobudi, L. (2015). Tingkat keberhasilan pembentukan buah tiga varietas tanaman tomat (Lycopersicon esculentum Mill.) pada lingkungan yang berbeda. Jurnal Produksi Tanaman, 3(8).

Musaddad, D., \& Hartuti, N. (2003). Produk Olahan Tomat. Penebar Swadaya. Jakarta, 310.

Silalahi, U. (1999). Metode dan Metodologi Penelitian

Sugiyono, M. P. K. (2005). Bandung. Affabeta, $C V$.

Supriati, Y., \& Siregar, F. D. (2015). Bertanam Tomat di Pot (Edisi Revisi). Penebar Swadaya Grup.

Umar H. 2008. Strategic Management in Action. Jakarta (ID): PT. Gramedia Pustaka Utama.

Widhiantari, I. A., Sutan, S. M., \& Djoyowasito, G. (2016). Rancangan Wadah Buah Tomat Untuk Menahan Getaran Selama Transportasi Berbahan Eceng Gondok dan Pelepah Pisang. The Indonesian Green Technology Journal, 5(1), 1-6.

Yanti, N. K. A. T. (2016). Panen Dan Pasca Panen Tomat (Licopersicum esculentum) dalam Mendukung Model Kawasan Rumah Pangan Lestari Di Kabupaten Badung. In Prosiding Seminar Nasional Inovasi Teknologi Pertanian.

Yola, M., \& Budianto, D. (2013). Analisis kepuasan konsumen terhadap kualitas pelayanan dan harga produk pada supermarket dengan menggunakan metode Importance Performance Analysis (IPA). Jurnal Optimasi Sistem Industri, 12(12), 301-309. 